\title{
Fetal sacrococcygeal teratoma
}

\section{Bellieni $\mathrm{CV}^{* 1}$, Molinaro $\mathrm{F}^{2}$, Sica $\mathrm{M}^{2}$, Angotti $\mathrm{R}^{2}$, Messina $\mathrm{M}^{2}$, Bocchi $\mathrm{C}^{3}$, Severi $\mathrm{F}^{3}$ and Carbone $\mathrm{S}^{4}$}

${ }^{1}$ Department of Mother and Infant, University Hospital, Siena, Italy

${ }^{2}$ Division of Pediatric Surgery, Department of Medical, Surgical and Neurological Sciences, University of Siena, Italy

${ }^{3}$ Division of Obstetrics, University of Siena, Italy

${ }^{4}$ Institute of radiology, University Hospital, Siena, Italy

An anterior myelomeningocele had been suspected in a female fetus on the basis of fetal ultrasonography; prenatal MRI at the $24^{\text {th }}$ week of gestation confirmed a cystic mass in the anterior sacrococcygeal

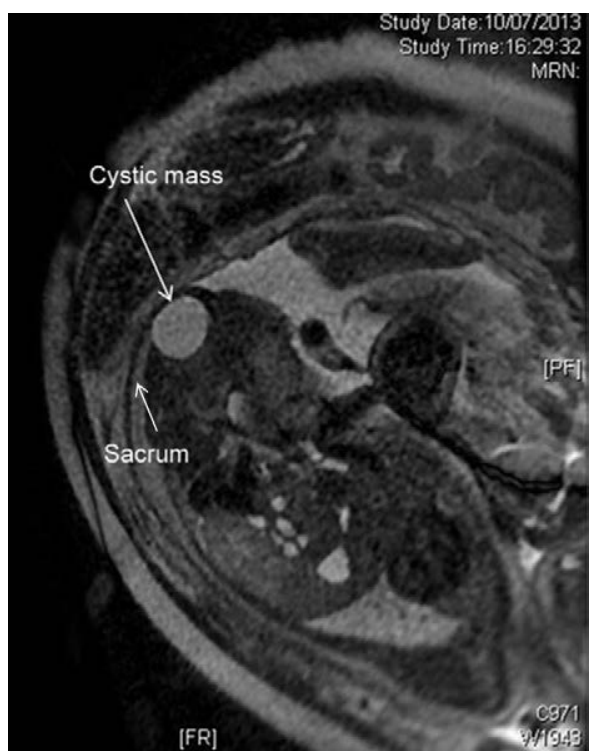

Figure 1. Prenatal diagnosis (fetal MRI): a tumor in the fetal sacrococcygeal area

Copyright: (C2017 Bellieni CV. This is an open-access article distributed under the terms of the Creative Commons Attribution License, which permits unrestricted use, distribution, and reproduction in any medium, provided the original author and source are credited. area [1]. The mass was surgically removed at one month of age, and hystopathological analysis determined it was a mature teratoma (Figure 1).
Correspondence to: Carlo Valerio Bellieni, Department of Mother and Infant, University Hospital, Siena, Italy, E-mail: cvbellieni@gmail.com

Received: May 04, 2017; Accepted: May 17, 2017; Published: May 20, 2017 